The authors ask whether the hypothesis of undertreatment has been tested by comparing the data of patients who received a modern antidepressant with those who were treated with a classic antidepressant (36 v. $82 \%$ sub-optimal dose). The design of the study with outcome measures only at discharge did not permit such an analysis because all patients who had more than one treatment usually received both a modern and a classic antidepressant, but analysis of subgroups in the sample may give an answer in the future.

Undertreatment, however, is not only low-dose treatment but also the tendency not to set a next step in the treatment strategy when incomplete recovery occurs.

T. J. Heeren University Hospital of Utrecht, Division of Geriatric Psychiatry of the HC Rümke Group. Oude Arnhemseweg 260. The Netherlands

P. Derksen Department of Geriatric Psychiatry of Zou en Schild, Amersfoort

B. F. v. Heycop Ten Ham, P. P. J. Van Gent Department of Geriatric Psychiatry of Bloemendaal, The Hague, The Netherlands

\section{BSE and human prion disease}

Sir: In his review of our current understanding of the possible relationship between bovine spongiform encephalopathy (BSE) and human prion diseases Harrison (1997) appears reasonably certain that "all potentially infectious material has been banned from the food chain" as a result of the 1989 Specified Offals Ban. I fear that his confidence on this point may be misplaced.

The Specified Offals Ban excludes organs which contain significant amounts of central nervous system tissue ante mortem, principally brain and spinal cord. However, the slaughter process itself, consisting as it does of significant brain trauma from a 'bolt', may result in embolisation of central nervous system tissue to other parts of the body around the time of death. This was graphically demonstrated by Garland et al (1996a), who found macroscopic quantities of brain tissue (confirmed histologically) in "the main pulmonary artery of $2.5-5 \%$ of cattle after slaughter" - the largest embolus found was $14 \mathrm{~cm}$ in length! Such brain embolisation is a long-recognised complication of both open- and closed-head trauma in humans (McMillan, 1956).
Despite a claim by the Ministry of Agriculture, Fisheries and Food (MAFF) that "there is ... no evidence that human lungs present a source of human exposure to bovine brain tissue in the UK" (Taylor, 1996), bovine lungs are legally permitted in certain meat products "sold for consumption without further cooking", such as salami and patés (MAFF, 1984). In addition, the British Veterinary Association, in a fax cited by Garland (1996b), confirmed that "it is perfectly legal for bovine lungs to enter the human food chain", and that "lungs can legally be sold in their fresh state".

Given Garland et al's findings, our stilllimited understanding of the risk to humans of the ingestion of prion-containing bovine tissue and the possible prevalence of currently incubating 'new-variant' CreutzfeldtJacob disease (Cousens et al, 1997), we should ensure that no part of any BSEinfected animal enters the human food chain, rather than merely excluding central nervous system tissue, as at present.

Cowsens, S. N., Vynmycyk, E., Zdadier, M., ot of (1997) Predicting the CJD epidemic in humans. Noture, 385, 197-198.

Gartand, T., Bawer, N. \& Balloy, M. (1996) Brain emboli in the lungs of cattle after stunning. Loncet. 348, 610

Gartand, T. (19966) Brain emboli in the lungs of cattle. Lancet. 348. 749.

Harrison, P. J. (1997) BSE and human prion disease. British Journal of Psychiotry, 170, 293-300.

Ministry of Agriculture, Fisheries and Food (1984) The Meat Products and Spreadable Fish Products Regulations. Statutory Instrument No. 1984. No 1566.

McMillan, J. B. (1956) Embolism of cerebral tissue in lungs following severe head injury. Americon fournal of Pathology, 32. $405-415$

Wylor, K. C. (1990) Brain emboli in the lungs of cattle. Loncet, 348. 749 .

J. G. Longhurst Department of Psychiatry, Yale University, 34 Park Street, New Haven, Connecticut 06519, USA

\section{Risk assessment and clinical risk management}

Sir: Reed (1997) states that risk factors for future violence are summative, and that the co-existence of mental illness, psychopathic disorder and substance misuse may present a very significantly increased risk. This is not necessarily so. A study of patients discharged from a special hospital (Jones et al, 1994) found that, specifically in the case of patients classified as psychopathically disordered, comorbidity in the form of mental illness or substance misuse significantly reduced the risk of further convictions for serious criminal offences after discharge.

We hypothesised that the existence of a psychotic illness, or substance misuse, could provide a focus for treatment, and a specific risk factor which could be reduced by treatment. In contrast, 'pure' psychopaths, for whom no definitive treatment may be available, and in whom improvement may be harder to quantify, are likely to represent a higher future risk to others.

Historical data, by its very nature, remain unchanged by the therapeutic process. Risk, in contrast, is dynamic, and accurate risk assessment must be able to modify actuarial consideration in the light of treatment response. Risk assessment is a complex procedure, relying crucially upon a detailed clinical understanding of an individual patient. General principles must always be considered only as a starting point for assessment, and factors which in general increase risk may, if amenable to therapeutic interventions, paradoxically serve to reduce that risk, if their impact on future behaviour can be altered.

Reed, J. (1997) Risk assessment and clinical risk management: the lessons from recent enquiries. British journol of Psychiotry. 170 (suppl. 32), 4-7.

Jones, C. N., MacCulloch, M. J., Bailey, J. \& Shahtemasabl, 5. (1994) Personal history factors associated with reconviction in personality disordered patients discharged from a special hospital. Journal of Forensic Psychiotry, 5. $249-261$

C. Jones Clwydian House, Archimedes Centre. Wrexham Technology Park, Wrexham LLI3 7YP

\section{Serotonin: $\mathbf{5}-\mathrm{HT}_{2 \mathrm{~A}}$ receptor occupancy in vivo and response to the new antipsychotics olanzapine and sertindole}

Sir: Up to a third of patients do not respond to typical antipsychotics which potently block-dopamine type $2\left(D_{2}\right)$ receptors. This treatment is often associated with distressing extrapyramidal side-effects. The novel atypical antipsychotic drugs clozapine, risperidone, sertindole and olanzapine appear relatively free from extrapyramidal sideeffects. It has been suggested that this is secondary to $5-\mathrm{HT}_{2 \mathrm{~A}}$ antagonism. In vitro and indirect evidence suggests that the ratio of $5-\mathrm{HT}_{2 \mathrm{~A}}$ to $\mathrm{D}_{2}$ blockade may be crucial to the clinical profile of atypical antipsychotics (Kapur \& Remington, 1996). 
Previous positron emission tomography studies find clozapine and risperidone both exhibit high cortical $5-\mathrm{HT}_{2}$ receptor occupancy in vivo in treated people with schizophrenia (Nyberg et al, 1996). Recently, 123I5-I-R91150, a novel, highly selective $5-\mathrm{HT}_{2 \mathrm{~A}}$ ligand for single photon emission tomography (SPET), has become available. We report the first SPET study of $5-\mathrm{HT}_{2 \mathrm{~A}}$ occupancy by two novel antipsychotic drugs, sertindole and olanzapine.

\section{Case report 1}

A. is a 39-year-old female. She has a 20year history of chronic psychosis fulfilling DSM-IV criteria for chronic schizophrenia. She had been well controlled for several years on depixol, reduced because of extrapyramidal side-effects. During dose reduction she had a florid relapse. A. became increasingly perplexed, thought-disordered and preoccupied with paranoid and selfreferential delusional ideas. She was no longer able to work, or live independently. She began sertindole and improved markedly, returning to work after three months of sertindole $12 \mathrm{mg}$ per day.

\section{Case report 2}

B. is a 23-year-old male with first episode DSM-IV schizophrenia. He was admitted to hospital with a two-year history of increasingly social withdrawal, isolation and irritability, referential and persecutory delusions. After five weeks of olanzapine $15 \mathrm{mg}$ per day his mental state had improved to the extent that he was considered fit for discharge. Staff noted he was less psychotic, calm and cooperative.
Both patients agreed to take part in research investigating $5-\mathrm{HT}_{2 \mathrm{~A}}$ receptor occupancy and antipsychotic response with SPET. Ratings were performed on the day of the scan. Subject 1 had a SCI-PANSS (Structured Clinical Interview for the Positive and Negative Syndrome Scale) score of 67 and subject 2 of 56 . Global Assessment Scale scores were 70 for subject 1 and 80 for subject 2. Neither patient scored on measures of abnormal involuntary movements, akathisia or extrapyramidal side-effects.

Our initial studies in five healthy subjects found that ${ }^{123} \mathrm{I}-5-\mathrm{I}-\mathrm{R} 91150$ images 5 $\mathrm{HT}_{2 \mathrm{~A}}$ receptors in vivo, with a frontal cortex to cerebellar ratio of $1.4 \pm 0.05$ (Busatto et al, 1997). Image acquisition is as reported in Busatto et al (1997). A brain dedicated SME 810 multidetector scanner for SPET acquired a whole brain multi-slice sequence at 120 minutes after the intravenous injection of $180 \mathrm{MBq}{ }^{123}$ I-5-R91150. At this time the cortico-cerebellar ratios are maximal and stable, representing pseudoequilibrium.

Region of interest templates were fitted to each scanning sequence and adjusted for brain size. Ratios of activity in cortical areas to the activity in the cerebellum, an area of the brain with few or no $5-\mathrm{HT}_{2 \mathrm{~A}}$ receptors, provided a measure of regional specific binding to $5-\mathrm{HT}_{2}$ receptors over time.

The frontal:cerebellum ratio for subject 1 was 0.86 and for subject 20.98 . These are far lower than the ratio of $1.4 \pm 0.05$ in healthy volunteers (Busatto et al, 1997). These ratios suggest a high degree of cortical $5-\mathrm{HT}_{2 \mathrm{~A}}$ blockade by both sertindole and olanzapine, similar to that seen in clozapinetreated individuals (Nyberg et al, 1996).

We believe that this is the first demonstration that sertindole and olanzapine potently occupy $5-\mathrm{HT}_{2 \mathrm{~A}}$ receptors in vivo, associated with a good clinical response. With regard to $D_{2}$ receptor occupancy, previous imaging studies have found that sertindole exhibits a higher degree of in vivo striatal $\mathrm{D}_{2}$ receptor blockade than olanzapine (Pilowsky et al, 1996, 1997). Here we report a high degree of $5-\mathrm{HT}_{2 \mathrm{~A}}$ blockade for both drugs. This supports the hypothesis that the ratio of $\mathrm{D}_{2}$ to $5-\mathrm{HT}_{2 \mathrm{~A}}$ blockade may protect against the appearance of extrapyramidal side-effects and promote antipsychotic action.

Busatto, G. F., Pilowaky, L. S., Costa, D. C., ex al (1997) Initial evaluation of |23-I-5-I-R9|150, a selective $5-\mathrm{HT} T_{2 A}$ ligand for single photon emission tomography (SPET). in healthy human subjects. European journal of Nuclear Medicine, 24, 119-142.

Kapur, S. \& Remington, G. (1996) Serotonin-dopamine interaction and its relevance to schizophrenia. Americon journal of Psychiotry, 153, 466-476.

Nybere, S., Nalcashima, Y., Nordatrom, A. L., ef of (1996) Positron emission tomography studies of in vivo binding characteristics of atypical antipsychotic drugs. Review of $D_{2}$ and 5-HT, receptor occupancy studies and clinical response. British journol of Psychiatry, 168 (suppl. 29), 40-44.

Pllowaky, L. S., Busatto, G. F., Tuylor, M., et of (1996) Dopamine $D_{2}$ receptor occupancy in vivo by the atypical antipsychotic olanzapine - a 123-1 IBZM single photon emission tomography (SPET) study. Psychophormocology 124. 148-153.

Pilowaky, L. S., O'Connell, P., Davies, N., (1997) In vivo occupancy of striatal $D_{2}$ receptors by sertindole - a 123 I IBZM SPET study. Journal of Psychophormacology, 10 (suppl. 3). A9.

M. J. Travis, G. F. Busatto, L. S. Pilowsky,

R. W. Kerwin Section of Clinical

Neuropharmacology, Institute of Psychiatry, Denmark Hill, London SE5 8AF

R. Mulligan, S. Gacinovic, D. C. Costa, P. J. Ell Institute of Nuclear Medicine, Middlesex Hospital, Mortimer Street, London WIN 8AA

J. Mertens, D. Terriere Vrije Universiteit Brussel - Eenheid, Cyclotron, B 1090 Brussel, Belgium

\section{One hundred years ago}

\section{The Lunacy Act, 1890, and its amendments}

The principal objects of the Lunacy Act, 1890 , were stated in the "Memorandum" to be to furnish safeguards against the improper confinement of persons as lunatics: to remove the difficulty then felt in securing the speedy treatment of mental disease; to amend the law as to single patients; and to put a check upon the establishment of new licensed houses. A second Amending Bill to the above Act being now before the House of Lords the time seems favourable for considering how far the objects aimed at in the original Act have been attained during the seven years it has been in operation. On the one hand, complaints are daily heard from asylum officials of the great difficulty they experience in carrying out the numerous, and, as some think unnecessary, provisions of the Act, and of the vastly increased amount of clerical and other labour which it entails; whilst, on the other hand, it is said that the Act is evaded, that secret, illegal, and irresponsible "treatment" of the insane, and those threatened with insanity, flourishes and 